\title{
Diabetes mellitus and arsenic exposure: a second look at case-control data from a Swedish copper
} smelter

\author{
Mahfuzar Rahman, Olav Axelson
}

\begin{abstract}
Objectives-To find out whether a newly found association between diabetes mellitus and arsenic in drinking water in Taiwan could be reproduced in copper smelters with arsenic exposure.

Methods-Extended analysis of a previous case-control study from 1978 was based on death records and objective exposure information from the company. The final analysis included only those employed at the smelter. Cases were 12 people with diabetes mellitus on the death certificate and those for whom there was clinical information on this disease. Controls were 31 people without cancer, cardiovascular and cerebrovascular disease as these disease categories had been associated with arsenic exposure in the original study and elsewhere.

Results-The odds ratios found for diabetes mellitus with increasing arsenic exposure categories were (reference level $=1$ ), $2 \cdot 0,4 \cdot 2$, and $7 \cdot 0$, but the $95 \%$ confidence intervals included unity. Unstratified test for trend was weakly significant, $P=0.03$.

Conclusions-Although based on small numbers, the findings provide some support for the suggestion that arsenic exposure could sometimes play a part in the development of diabetes mellitus.
\end{abstract}

(Occup Environ Med 1995;52:773-774

Keywords: cardiovascular disease; hygiene standard; occupational exposure

A relation between diabetes mellitus and arsenic in drinking water in Taiwan was recently suggested by Lai et al. ${ }^{1}$ To support this possible relation Lai et al, among other studies cited a paper from 1978 on Swedish copper smelters. ${ }^{2}$ As the files of this study, more than 17 years old, have been preserved, we decided to check whether there was any relation between arsenic exposure and diabetes mellitus in this material.

Department of Occupational and Environmental Medicine, University Hospital, 58185 Linköping, Sweden Mahfuzar Rahman Olav Axelson

Correspondence to: Professor Olav Axelson, Department of Occupational and Environmental Medicine, University Hospital, 58185 Linköping, Sweden.

Accepted 11 July 1995

\section{Material and methods}

This report is based on the same data set as the previous study ${ }^{2}$ - that is, the death records for the years 1960-76 in the parish of $S: t$ Orjan in northern Sweden, where the copper smelter is located. The local register of deaths and burials provided the diagnoses from the death certificates along with necessary data for identification of the men in the company files.

During the study period, 369 male deaths were recorded in the parish between the ages of 30 and 74 years. In the previous publication $^{2}$ we excluded 44 of these men because of vague diagnoses or because of diabetes mellitus in the death record. As we were not concerned with diabetes mellitus, there was good reason for this exclusion because of the well known association between diabetes mellitus and cardiovascular disease and because of the possibility that diabetes mellitus might have disqualified the man from applying for a job at the smelter. If so, the exposure frequency in the study base would not have been properly reflected when including diabetic men.

In this paper we have focused on diabetes mellitus and included as cases those men for whom this disease appeared on the death certificate. We also took into account clinical information from the health care unit of the company about diabetes mellitus in five men who had been employed. As we had no clinical information for those not employed in the smelter, the study base was restricted to only those who had been employed. As in the previous study, ${ }^{2}$ to obtain a proper representation of the exposure distribution in the study base, we accepted as controls only subjects free from diagnoses related to arsenic - that is, any kind of cancer, cardiovascular and cerebrovascular disease. It may be noted here, that different diseases may be compared with the same properly selected and representative control group, irrespectively of whether several diseases occur in the same person or not. Here we have considered diabetes mellitus, whereas the previous study accounted for other diseases in relation to arsenic exposure (cancer, cardiovascular and cerebrovascular disease).

We used the same objective exposure information and categories as in the earlier study. ${ }^{2}$ This information was provided by a safety engineer with long experience in the smelter. Three different categories of exposure were distinguished in relation to the hygiene standard for arsenic at the time, $0.5 \mathrm{mg} / \mathrm{m}^{3}$ of air. Category I refers to exposures considerably below $0.5 \mathrm{mg} / \mathrm{m}^{3}$, category II includes exposures close to but not exceeding $0.5 \mathrm{mg} / \mathrm{m}^{3}$ and category III means exposures above 0.5
The statistical analyses of the data were based on the Mantel-Haenszel procedure ${ }^{3}$ and its extension for testing the trend. ${ }^{4}$ In the trend test the scores for the exposure categories were taken as $1,2,3$, and 4 , respectively. 
Exposure to arsenic among men with diabetes mellitus and controls who had died of disorders unlikely to be related to arsenic exposure; all men were employed in a Swedish copper smelter

\begin{tabular}{|c|c|c|c|c|c|c|}
\hline \multirow[b]{2}{*}{ Ages } & & \multirow[b]{2}{*}{ Unexposed } & \multicolumn{4}{|c|}{ Arsenic exposure category } \\
\hline & & & $I$ & II & III & Total \\
\hline \multirow[t]{2}{*}{$30-54$} & cases & 0 & 1 & 0 & 0 & 1 \\
\hline & control & 6 & 1 & 1 & 0 & 2 \\
\hline \multirow[t]{2}{*}{$55-64$} & cases & 0 & 1 & 2 & 1 & 4 \\
\hline & control & 2 & 3 & 2 & 1 & 6 \\
\hline \multirow[t]{2}{*}{$65-74$} & cases & 2 & 0 & 1 & 4 & 5 \\
\hline & control & 6 & 3 & 2 & 4 & 9 \\
\hline \multirow[t]{2}{*}{ Total } & cases & 2 & 2 & 3 & 5 & 10 \\
\hline & control & 14 & 7 & 5 & 5 & 17 \\
\hline \multirow{2}{*}{$\begin{array}{l}\text { Crude odds } \\
\text { ratio } \\
95 \% \text { CI } \\
\text { Mantel-Haenszel } \\
\text { Odds ratio } \\
95 \% \text { CI }\end{array}$} & & $(1 \cdot 0)$ & $\begin{array}{l}2 \cdot 0 \\
0 \cdot 1-27\end{array}$ & $\begin{array}{l}4 \cdot 2 \\
0 \cdot 3-54\end{array}$ & $\begin{array}{l}7 \cdot 0 \\
0 \cdot 7-79\end{array}$ & $\begin{array}{l}4 \cdot 1 \\
0.6-33\end{array}$ \\
\hline & & $(1 \cdot 0)$ & & & & $\begin{array}{l}3 \cdot 3 \\
0.5-30\end{array}$ \\
\hline
\end{tabular}

Mantel extension for trend (total stratum), $X^{2}(1)=4.68 ; P=0.03$

\section{Results}

Out of the 369 men included in this study, 253 had not been employed at the smelter. Twelve had an indication of diabetes mellitus on the death certificate. Among the remaining 116 subjects who were employed at the smelter, seven had diabetes mellitus on the death certificate (odds ratio (OR) $1.3 ; 95 \%$ confidence interval (95\% CI) 0.49-3.4). Including the clinical information, 12 of the employed men had diabetes mellitus. Ten of the cases were exposed, among whom were all five clinically known cases; four of these were in the highest exposure category and one in the next but highest category.

There were only 31 controls, men with causes of death unrelated to arsenic exposure, out of whom 17 were exposed. There seemed to be a significant trend for risk of diabetes mellitus (table), but the $95 \%$ CI included unity for all exposure categories. To find out whether the excess of cardiovascular disease among the smelter workers could be related to diabetes mellitus, we also excluded the clinically known cases with diabetes mellitus from the cases of cardiovascular disease enrolled in the earlier study. ${ }^{2}$ The risk of cardiovascular disease reported in that study remained essentially unchanged.

\section{Discussion}

This small scale study was initiated by the suggestion of Lai et $a l^{1}$ that there might be a relation between arsenic exposure and diabetes mellitus and because they cited our earlier study ${ }^{2}$ in spite of the fact that it lacked specific information on this disorder. This reconsideration of the data for that study seems to support their findings, even though the numbers are inconclusively small.

There is no indication that the excess of car- diovascular disease as previously seen in the smelter workers should be just secondary to diabetes mellitus. Although likely that not all clinical cases are known to us, this lack of information is hardly related to the degree of exposure and should therefore not create the trend in risk that appeared in this reconsideration of the data. The inclusion of clinical information on diabetes mellitus in some subjects might be looked upon with some scepticism. We have no indication, however, that those with high arsenic exposure should have been kept under more careful medical surveillance than others. Nor do the clinical cases carry all the excess risk seen in these data.

With regard to arsenic as a possible cause of diabetes mellitus, it is of interest that Boquist et $a l^{5}$ found some degeneration and necrosis in the $\beta$ cells of mice injected with hydroxylamine plus arsenite. The relevance of this experimental result to smelter workers is not clear. Smelter workers are exposed to trivalent inorganic arsenic compounds and may have urine values of a few hundred $\mu \mathrm{g}$ of arsenic/l, mainly excreted as dimethylarsenic acid. ${ }^{6}$

As reviewed elsewhere, ${ }^{6}$ arsenic is widely distributed in a large number of minerals. Arsenic concentrations in the earth's crust are usually around $1.5-2 \mathrm{mg} / \mathrm{kg}$ and arsenic is mainly transported in the environment by water. Occupational exposure to arsenic occurs mainly among smelter workers and workers engaged in the production and use of pesticides containing arsenic and among glass workers. Drugs containing inorganic arsenic have been used for the treatment of leukaemia, psoriasis, and chronic bronchial asthma and as a tonic, usually at a dose of several hundred $\mu \mathrm{g}$ daily. Wine and mineral waters can sometimes contain several hundred $\mu \mathrm{g}$ of arsenic $/ \mathrm{l}$, for wine probably to some extent a result of the use of pesticides containing arsenic. These various sources of exposure might be considered as a background for additional studies to confirm or refute these first indications of a diabetogenic effect of arsenic.

1 Lai M-S, Hsueh Y-M, Chen C-J, Shyu M-P, Chen S-Y, Kuo T-L, et al. Ingested inorganic arsenic and prevalence of diabetes mellitus. Am F Epidemiol 1994;139:485-91.

2 Axelson $\mathrm{O}$, Dahlgren E, Jansson CD, Rehnlund SO. Arsenic exposure and mortality: a case referent study from a Swedish copper smelter. $B r \mathcal{F}$ Ind Med 1978; 35:8-15.

3 Mantel N, Haenszel W. Statistical aspects of the analysis of data from retrospective studies of disease. 7 Natl Cancer Inst 1959;23:719-48.

4 Mantel N. Chi-square tests with one degree of freedom: extensions of the Mantel-Haenszel procedure. American extensions of the Mantel-Haenszel procedure.

5 Boquist L, Boquist S, Ericsson I. Structural beta cell changes and transient hyperglycaemia in mice treated with compounds inducing inhibited citric acid cycle with compounds inducing inhibited

6 World Health Organization. Environmental health criteria 18: arsenic. Geneva: World Health Organization, 1981. 